\title{
Hedonic Pleasure and Social Image: The Effectiveness of Internet Advertising
}

\author{
Azizul Yaakop ${ }^{1} \&$ Jane Hemsley-Brown ${ }^{2}$ \\ ${ }^{1}$ Faculty of Management and Economics, Universiti Malaysia Terengganu, Malaysia \\ ${ }^{2}$ Faculty of Management and Law, University of Surrey, England \\ Correspondence: Azizul Yaakop, Faculty of Management and Economics, Universiti Malaysia Terengganu, \\ Malaysia. E-mail: azizul_yadi@umt.edu.my
}

\author{
Received: September 26, 2012 Accepted: October 11, 2012 Online Published: December 31, 2012 \\ doi:10.5539/ass.v9n1p179 URL: http://dx.doi.org/10.5539/ass.v9n1p179
}

\begin{abstract}
Online travel promotions and campaigns have intensified in recent years and the use of social media sites (SNS) in promoting tourism destinations is also increasingly common worldwide. However, knowledge of the efficacy of this media approach is still somewhat limited but is fundamental and essential as part of employing the Internet as one of the media for advertising purposes, especially for a country that is highly dependent on the tourism industry. Understanding of the functions, mechanisms and uses of internet advertising targeted at international tourism consumers is important, but currently theoretical models are limited to generic perceptions of advertising media across all media and all buying categories. This paper presents the findings from a study which focuses on the advertising belief factors (i.e. product information, hedonic/pleasure, social role/image and falsity/no sense) that significantly explain tourists' attitudes towards advertising specifically, internet advertising. The study reported in this paper is a quantitative survey based on a sample of 425 respondents, 255 are international tourists $(60 \%)$ and 170 are local visitors $(40 \%)$. The study reveals other factors which have seldom been reported in previous research. $A_{\text {Internet }}$ effectiveness is influenced by the capability of internet advertising to bring fun and entertainment (hedonic/pleasure); and to reflect consumers' social and self image (social role/image). The implications of the study focus on consumers' perceptual shift in terms of media consumption and on the relevance of social network sites (SNS) in promoting tourism destinations. The limitations of the study are also discussed.
\end{abstract}

Keywords: advertising, internet advertising, social networking, international tourism, hedonism

\section{Introduction}

The impact of the Internet as a powerful communication medium cannot be disregarded. Recent data on the growth of the Internet indicate that this medium demonstrates a massive media influence in today's everyday transactions. The number of users connected to the Internet is growing at an increasing rate every year. Recently, the number of internet users was recorded at a massive 1.9 billion worldwide in the first half of 2010 (http://www.internetworldstats.com). There has been accumulative increase of 445 per cent in the average growth in internet users globally over the past ten years (i.e. from 2000 to 2010). Due to this fact, advertisers are determined to pursue advertising on the Internet and by all means, and consumers, particularly tourists, are believed to place a certain degree of reliance on online advertisements when it comes to making decisions, regardless of whether they are tourism-related. Even in the context of Tourism Malaysia itself, the launch of the latest Tourism Malaysia internet advertising was claimed to reflect the significance of the Internet as the most preferred media platform from which travellers can obtain travel information (http://www.domain_b.com). This also corresponds with previous literature that highlights the importance of the Internet as the next marketing tool to advance tourism (Wu et. al. 2008; Mills et. al. 2007). Hence, Malaysia tourists' attitudes towards advertising on the Internet are essential in acknowledging tourists' initial perceptions towards the use of social networking sites (SNS) in promoting tourism destinations.

The massive growth of media usage in this era has given mixed signals to advertisers as well as to academics. The popularity of the Internet and the escalating use of SNS, for example, have opened up many opportunities in terms of what advertisers can offer to the public. The concept of interactivity and the use of the Internet as 'a hybrid of television, radio, newspaper, magazines, billboards, direct mail, and so forth’ (Miller 1996) are 
apparently more outstanding and prominent than the traditional media - printed and televised forms. Despite the overall positive connotations, however, internet advertising is also being brought into dispute due to the excessive amount of infuriating ads or scams in online marketing. This situation has created unnecessary attention and negativity towards advertising, which sends a bad signal to the advertisers.

In the current intense market competition, deep consideration about the ubiquitous nature of advertising should be a matter of importance and a priority for advertisers when making their media selection. It is very critical for advertisers to select an appropriate medium or set of media to get their advertising messages across to different levels of audiences without creating undue negativity towards this form of marketing communication. All in all, advertisers should understand the forms of relationship that consumers have with advertising and advertising media, as they demonstrate how the consumers form bonds with advertising, particularly in different sets of media.

\section{Advertising on the Internet}

The advent of the Internet represents a phenomenal revolution in the history of mass communication technology since the introduction of television. Even though television had a higher early acceptability rating than the Internet, the number of people connecting to the Internet has accelerated every year. This positive trend corresponds with the increasing usage of the Internet as one of the marketing communications media, alongside the traditional ones. Jayawardhena et al. (2007) posited that consumers' propensities for using the Internet and other traditional media for purchasing orientation largely follow similar patterns; for this reason, they advise marketing practitioners to treat digital media as extensions of the existing traditional marketing activities.

Unlike during the Internet's fledgling years, the trend for using the Internet in daily activities nowadays has not only affected the upscale, young market in the developed countries but is also now spreading among the lower-income groups, as digital media are now easily accessible and affordable all around the world (Chaffey 2009). The growing popularity of the internet blogs, social media sites and the increasing demand for broadband facilities are some of the factors accelerating the overall growth of internet usage worldwide (http://www.internetworldstats.com). Despite its acceptability rate, which is much lower that television when it was first introduced, its multidimensional adaptability coupled with massive worldwide connectivity could potentially make the Internet a highly reliable and powerful communication medium.

By the 1990s, with the astonishing volume of activity on the Internet and its ability to transform a communication medium into a customized means of interaction, not only between marketers and consumers but also among consumers (Walmsley 2007), many companies came to appreciate the potential of the Internet as another medium of advertising and were further persuaded to venture into internet advertising (Leiss et al. 2005). It is important to note that the motivation to pursue online advertising on the Internet runs parallel to the concept of 'consumer relationship management', which is one of the core functions embodied in the e-marketing environment (Chaffey 2007). In comparison with the traditional media, the Internet not only acts as a powerful two-way communication tool but is also used as a point where important consumers information is collected and stored, orders are placed and payments are made. This multitasking function has made the Internet a more influential multifunctional medium for delivering not only marketers' messages but also forums for consumers to generate alternatives prior to making decisions (Walmsley 2007). Due to this multitasking nature, the Internet constitutes a new generation of hybrid media. Even in the early years following its invention, Miller (1996) claimed that the Internet is a convergence of all other media, that is, a hybrid of television, radio, newspapers, magazines, billboards, direct mail and so forth.

Although this new media form is regarded as a combination of all media, Chaffey (2007) underlined six characteristics of digital media that make them different from the traditional ones (also known as ' 6 Is'):

Firstly, internet media are characterized by their ability to generate interaction between marketers and consumers as well as among consumers (Walmsley 2007). In pursuing online advertising, advertisers create online traffic by providing incentives such as online promotions where consumer responses in the form of personal data are recorded, stored and managed.

Secondly, internet media are characterized by intelligence attributes when conducting market research and collecting personal information from the consumer, with a relatively lower price tag than the traditional media. This ability opens up opportunities for marketers to develop customer profiles and enables them to further process the information, for example, to build existing customer profiles for regular purchases of other competing or complementary brands. As a matter of fact, through the availability of social networking sites (SNS) in the online environment, marketers are now able to gather and disseminate information important to develop potential customers' profiles. However, this is subject to control mechanisms set by the consumers to effectively 
receive and share information and some external factors influencing ad avoidance in SNS.

Thirdly, internet media are characterized by their ability to have the means of communication purposely tailored to a specific individual. This feature is indeed of paramount importance in maintaining a good customer-based relationship for online marketers because personalized attention has a propensity to instantly capture consumers' interest. However, the idea of having personalized communications in digital media is now being challenged by the development of social networking sites (SNS). Tony Effik of Publicis Modem New York, as reported in ADMAP March 2011, suggested that social targeting of communities and the influencers within those social groups is indeed the way forwards for the internet media (ADMAP 2011).

Fourthly, these digital media are able to integrate other marketing communications tools. More often than not, marketers employ the Internet to facilitate customers' feedback on promotions advertised on other media or after sales services. It is the convenience factor of the internet media among online users for communicating feedback that makes it practical to have them integrated with other forms of media. This notion corresponds with the pervasive view that internet users are principally motivated by convenience (Jayawardhena 2007).

Fifthly, the Internet offers disintermediation and reintermediation, which are parallel with the key concept of industry restructuring. The Internet provides an avenue for marketers either to have a direct relationship with their customers or to have a selection of intermediary sites which could be associated with their common goals and objectives. Although disintermediation is likely to occur in the electronic environment, the latter will, in turn, provide a core competitive advantage for marketers in the e-marketing environment to encourage affiliations with brands that possess more established reputations.

Finally, digital media are characterized by their omnipresence in the global market, or their independence of location. With the ever increasing significance of globalization, the Internet gives marketers the advantage of having virtual access to places or countries to which there is otherwise limited or restricted access via traditional media. This feature also provides a cost-effective means of ensuring the presence of products or services in the market without the necessity of having sales forces physically in position.

As mentioned earlier in this section, the level of internet access around the world is increasing at an exponential rate (http://www.clickz.com/stats). With the characteristics of these digital media in mind, most advertisers employ the Internet as another powerful advertising medium because of its ability to gain massive exposure in every part of the world. Although sceptics may see this trend as an origin of ad proliferation that scares internet users with millions of online advertisements and invades their privacy, many practitioners have come to appreciate this predicament and have tried to remedy it by producing multiple user-friendly ad formats; for example, pop-up boxes invite the users to click in order to find out more about the advertised product. This technique was claimed to be more accessible and less intrusive. In addition, apart from allowing the materials on the Internet to gain worldwide access, the Internet also has the capability to segment customer selectivity in the sense that it customizes sites that gain attention of a very specific well-defined target market. The use of internet search engines and various other ad formats, such as pop-ups, banners and skyscrapers, facilitate online transactions and are important characteristics that influence online advertising response (Burns and Lutz 2006). Secondly, online advertisements apply the 'pull' advertising concept which allows online customers to voluntarily learn about and compare brands more easily and quickly than by conventional shopping (Chaffey 2007; Duncan 2002). This concept is important to customers and has essentially shifted power from companies to consumers in that they are able to assess a plethora of information on virtually any subject or brand prior to purchase behaviour (Duncan 2002). Furthermore, the Internet allows all information on the website to be delivered 24 hours a day, seven days a week and at the comfort and convenience of the viewers. In addition, it has the ability to allow advertisers to keep track of the numbers of visitors to their websites and to have virtually constant interaction with the customers via the contact section (O'Guinn et. al. 2006). Lastly, although the cost of producing and placing an advertisement on the internet may be higher than any other forms of advertising media, the cost will be stretched over a longer period of time and will thus be lower over a considerable span of time. In short, the Internet is very different from the traditional media and offers multiple advantages such as constant message delivery, audience selectivity, multimedia capacity, measurable effects, global reach, audience-controlled advertising exposure and interactivity (Wolin et. al. 2002).

Frequently, this medium has been endowed with extravagant stories to make it seems perfect from every angle but, as far as internet advertising is concerned, it is noteworthy that its impact on advertising spend has been minimal (Leiss et al. 2005). Although it was first introduced in the 1960s for military networking tasks, the public only started to explore the Internet in the late 1980s. Nowadays, many companies are involved in internet advertising as 
usage of the Internet grows, and the market is becoming more dependent on the internet application, especially in brand-searching.

However, this notable potential comes with a few alarming setbacks. One of them is related to the issue of customer security and privacy (Arens 2006). Online customers are not totally convinced about the content and accuracy of information in internet transactions, as online scams and internet forgery are still occurring. Branthwaite et al. (2000) referred to consumer perceptions of the Internet as exciting but inherently malevolent, dangerous and frightening due to general suspicion about its content. Kateranttanakul (2002) stressed that internet users perceive lower risks if the content of the website is accurate and reliable, which in turn will facilitate an optimal decision-making process. In a more recent article, Wu et al. (2011) found that consumers' attitudes towards internet advertising were positively and significantly influenced by two antecedents, one of which was their concern about the advertising content. This matter brings up the question of trust in the online environment, especially in regard to the lack of trust in internet merchants that do not have established reputations (Lee and Turban 2001). Although this issue is fairly common, marketing academics have tried to understand how to inspire consumer trust in the online shopping setting. Cheung and Lee (2006) and Lim et. al. (2006) found that peer endorsement was an effective means of developing trust among online shoppers. Cheung and Lee (2006) also highlighted the important of creating trust through the use of security features on the website. These protocols exemplify the importance of maintaining sound customer relationship management by instilling consumer trust.

The environment in regard to advertising on the Internet is being influenced primarily by technological advancements. As a result of a rapid development in science and technology, much of the revolutionary technology especially germane to marketing communication channels can be made available online very quickly. With this matter in hand, it is therefore worth focusing on the areas which the Internet, as a marketing communications medium, has recently revolutionized. One of the evolutions in internet advertising over the past five years is the incorporation of social media as an integral part of the promotional mix (Mangold and Faulds 2009). The idea of using social media websites such as Facebook, Twitter and Youtube to disseminate product information is related to the capability of these websites to facilitate positive word-of-mouth (eWOM) among established social networks. In consistency with the topic of trust in the online environment as mentioned earlier, the use of social networking sites (SNS) will provide a potential avenue for marketers to counter the problem of consumers' lack of trust in online shopping. Chu and Kim (2011) discovered that trust is one of the social relationship constructs that has a positive and significant impact on eWOM in SNS. They opined that eWOM behaviour has increased in SNS due to users' willingness to rely on their social connections on the 'friends' list.

At first glance, the purpose of SNS in the online advertising environment is to provide an alternative medium for marketers as a brand builder, especially in a setting where a community-oriented environment is of paramount importance in developing consumer trust. However, leveraging SNS as an effective advertising medium to create brand awareness has also been questioned. Through many forms of consumer empowerment, cognitively or behaviourally (e.g. from ignoring ads to deleting pop-ups), it is now essential for marketers to understand the conditions under which internet users are likely to avoid internet advertising through the use of SNS. Kelly et. al. (2010) found that teenage internet users are likely to avoid advertising in the online social networking environment if they (i) have expectation of a negative experience, (ii) think that the advertising is irrelevant, (iii) feel doubtful about the advertising message and (iv) are sceptical about the advertising medium. Therefore, it is worth mentioning that employing social media is not totally satisfactory in many cases. Indeed, marketers need to have a really firm definition of social media sites as advertising media and address their relevance and credibility to their target markets (Kelly et. al. 2010).

The next section will review some studies that have focused on consumers' attitudes towards advertising on the Internet. It is important to note that the arguments in the following sections are fundamental for establishing the theoretical foundations of this research.

\section{Attitudes towards Advertising on the Internet}

The Internet, or World Wide Web (WWW), is regarded as a new advertising medium which is characterized by ease of entry, relatively low set-up costs, global accessibility, time independence, and interactivity (Berthon et. al. 1996). Consequently, this medium creates a worldwide opportunity for advertisers to deliver fast and timely messages at a low cost. Recent data on the growth of the Internet has proved that this medium demonstrates a massive media influence in today's everyday transactions. As mentioned earlier, the number of users connected to the Internet is increasing dramatically every year. The nature of the Internet as a medium with high-speed interactive capability could be one of the factors contributing to this increasing number of users. Coupled with its ability to virtually manage one-to-one communication and to facilitate speedy and instant information exchange 
regardless of time and distance, it is not surprising that advertisers regard it as the next potential medium to exploit (Ducoffe et al. 1996). As a matter of fact, advertising content is one of the biggest segments on the Internet and it is growing at a remarkable rate every year, resulting in a total of 21.2 billion dollar for the full year of 2007 in the United States alone (http://www.iab.net). With the prospect of huge potential returns on the advertisers' side and the simplicity of engaging in business as well as personal transactions on the users' side, the Internet is expected to be the market's future preference for upcoming communication media. However, can these strong points be instrumental in influencing people's attitudes towards advertising on the Internet?

Internet advertising, electronic advertising or web advertising has seldom been defined in past studies. Hawkins (1994) used the term electronic advertising to refer to advertising that is delivered to users of electronic information services.

\begin{abstract}
"Internet advertising is described broadly as any form of commercial content available on the internet that is designed by businesses to inform consumers about a product or service. Hence, internet advertising can be delivered via any channel (e.g. video clip, print or audio), in any form (e.g. an e-mail message or an interactive game), and provide information at any degree of depth (e.g. a corporate logo or an official Web site)". (Schlosser and Shavitt 1999)
\end{abstract}

In juxtaposition with the general definition of advertising, Wolin et. al. (2002) explained that internet advertising comprises commercial content paid for by sponsors, designed for audiences, and delivered by video, print, audio, graphics or animation; it may be solicited or unsolicited. Cho (1999) explained the concept of interactivity in internet advertising and emphasized that advertising exposure on the Internet is different from the type that individuals come across in traditional media. Individuals may experience non-voluntary advertisement exposure on television or in any other traditional media; this causes program interruptions and annoyance, thus resulting in negativity toward the media. The Internet, however, offers both voluntary and non-voluntary advertising exposure depending on the types of Web advertising (Cho 1999) and this may lead to comparatively more favourable consumer perceptions of advertising on the Internet. Consumers also form perceptions on the basis of advertising value from the media stand-point. That is to say, an advertising medium with a greater potential for consumer benefits and opportunity to serve consumers well will likely be viewed as superior to the others. Attitude formed by consumers towards advertising on the Internet is defined in this study as:

\title{
A learned predisposition to respond in a consistently favourable or unfavourable manner toward advertising on the Internet.
}

Ducoffe (1996), in his survey, examined the early adopters of the Internet to assess internet advertising on the basis of its value to consumers. Due to the fact that internet adoption was still in its early stages in that particular era, the research had found less domination by the Internet over the other advertising media. The findings also suggested that the traditional advertising media attributes, such as informativeness, entertainment and irritation, remained significant and directionally consistent as predictors of consumers' valuation of advertising. Indeed, the relationship between these advertising values and overall attitude toward web advertising was also significant and supported by the data. These results clearly showed that the attitudes held by the consumers towards advertising in any media reference have a significant impact on the overall attitudes towards advertising.

In 1999, Schlosser and Shavitt (1999) ran two factor analyses on 16 attitudinal items to measure their relationships with overall attitudes towards internet advertising. They found the items yielded on five predicted factor components: advertising utility, indignity, trust, price perceptions and regulation. Even though the findings showed internet users' mixed perceptions of internet advertising, it is important to note that the overall construct of internet users' attitudes towards advertising was further supported. As a matter of fact, a further regression analysis indicated that 43 per cent variance of the overall internet advertising attitudes could be explained by one of the five factor components alone: advertising utility Schlosser and Shavitt (1999). At a glance, internet advertising was viewed unfavourable as compared to advertising in general; however, a closer look at some specific key items revealed more favourable perceptions of internet advertising. On the whole, the authors found that internet users generally felt that internet advertising was more informative, trustworthy, and less intrusive than the other media. However, they also felt that internet advertising was less entertaining and does not help much in encouraging purchasing, although it provided relatively trustworthy information. It is noteworthy that the study placed its results side by side with those of another study with a demographically matched sample who answered the same questions in gauging perceptions of advertising in general. And, as expected, a number of contradictory patterns emerged, particularly in people's views on the ability of advertising to increase product prices (internet users perceived that internet advertising does not increase product prices). However, similarities can also be traced, 
especially when exploring people's views on government intervention in advertising regulations; both samples wanted the advertising industry to control the regulations.

Brackett and Carr (2001) extended the previous literature by adding two more variables to strengthen the theoretical model on people's attitudes towards internet advertising as compared to other media. The two new variables were credibility and relevant demographic variables. Credibility was considered another perceptual antecedent because of its significance as a predictor that explained attitude towards advertising in another model proposed by MacKenzie and Lutz (1989). The second innovation was the inclusion of relevant demographic variables. The authors justified the use of a student sample, claiming that relevant demographic variables such as college major and gender have impacts on students' perceptions of advertising value and attitudes towards advertising. Even though little can be gained in comparing the study with the previous one, i.e. Ducoffe (1996), the end results certainly provided options in examining attitudes towards advertising, especially in incorporating some relevant demographic variables, which added greater information to explain attitudes towards advertising (Brackett and Carr 2001).

In brief, the previous studies on attitudes towards adverting on the Internet have mainly focused on the acceptance level of consumers as the users of the services. Despite the growing number of studies on internet acceptance, researchers have seldom been inspired to examine the perceptions of other relevant parties who could be central to making the Internet an effective medium of advertising. For this reason, there has been a dearth of emphasis placed on the perceptions of the policy-makers or the advertisers on the effectiveness of internet advertising. Although this may not be of direct interest to the current study, perception of other relevant parties on internet advertising could give insights into the development of a new theoretical model. The perceptions of the Internet among a cross-section of advertising agencies and client organizations was first investigated by Bush et. al. (1998) in order to better understand the roles that the Internet plays within a marketing organization. Although conceptual frameworks to support the hypothetical propositions were non-existent, it was interesting to observe the advertisers' perception of the Internet as a medium of advertising. Ironically, in the midst of the overwhelming acceptance of the Internet among advertisers, the results of the data analysis showed that advertisers were uncertain about the Internet's ability to provide any kind of competitive advantage (Bush et al. 1998). Lack of confidence in delivering to an appropriate target audience might be the reason for this finding. Another study exploring how Web managers perceive the effectiveness of the web site as compared to eight other traditional media was carried out by Leong et al. (1998). In their study, Leong et. al. (1998) used ten key media attributes to measure the gaps between the media in a two-dimensional perceptual map. For the purpose of the current research, it is important to note that the Web managers perceive the web site (the Internet) as comparable to Direct Mail media as a source for delivering rich information, and it is not effective for stimulating emotions, unlike the television.

From the above fruitful discussion of existing literature, the present study has accumulated sufficient verifications to come up with an appropriate hypothesis to accompany the theoretical foundation of attitude towards advertising on the Internet $\left(\mathrm{A}_{\text {Internet }}\right)$. Leong et. al. (1998) developed a perceptual map to compare the effectiveness of the website with other traditional media and discovered that web site was placed closer to the rational dimension $v i s-\grave{a}-v i s$ the emotional dimension. This finding was similar to those of other previous research that the Internet has the ability to deliver rich information and detail which is also synonymous with other traditional media such as print media (Schlosser and Shavitt 1999; Ducoffe 1996; Brackett and Carr 2001; Lei 2000). Indeed, in a more recent study, Wolin et. al. (2002) also discovered that the product information role held the most dominant role in web advertising. Therefore, it is hypothesized that:

Hypothesis: Malaysia tourists' beliefs about internet advertising as a source of product information are positively related to attitude towards advertising on the Internet.

\section{Method}

A thorough assessment of conceptual and metric equivalence of the measures is important as the current research is investigating a group of samples across different nationalities. Firstly, in order to materialize the conceptual equivalence of the measures, two sets of questionnaires were produced in English and in Malaysia's national language through a careful process of back-translations (Berry, 1980). The questionnaire was first developed in English with reference to the main literature, which comprised the studies by Petrovici and Marinov (2007) and Tan and Chia (2007). Additional items were also taken from other previous literature in order to develop a distinctive scale best suited to the current setting. In consistency with Berry (1980), the questionnaire was then translated into the Malaysian language and back-translated into English by a third party to ensure consistency.

The researcher raises concern about the instrument, which may suffer from common method bias, since the 
design of this questionnaire requires same-respondent replies for both predictor and criterion variables. Common method variance (CMV) is "variance that is attributable to the measurement method, rather than to the constructs the measures represent" (Podsakoff et. al. 2003). However, in order to diminish the problem or minimize the likelihood of CMV, Podsakoff et. al. (2003) suggested four remedies, one of which was taken into consideration by this research. In this research, the remedy was undertaken at the ex ante research design stage where different scale endpoints and formats were recommended (for both predictors and criterion variables). The description of the remedy is as follows:

Firstly, there are two types of format used in the survey design, i.e. a 7-point semantic differential scale and a 5-point Likert scale. Secondly, different adjectival pairs were introduced to measure different attitudinal constructs. For example, attitude toward the institution of advertising ( $\mathrm{A}_{\text {Institution }}$ ) is measured by worthless/valuable, unimportant/important and necessary/useless, whereas attitude toward the instruments of advertising $\left(\mathrm{A}_{\text {Instrument }}\right)$ is measured by sincere/insincere and unethical/ethical (refer Appendix). Thirdly, negatively-worded items and inversion of scales were further suggested, so that the respondents could not easily combine related items to cognitively form the correlation needed to produce a CMV-biased pattern of responses (Murray et. al. 2005). For example, $\mathrm{A}_{\text {Instrument }}$ is measured by two 7-point semantic differential scales where the arrangement of both adjectival pairs is inverted.

Soon after the questionnaire was developed, a pilot study was conducted in the United Kingdom over a period of two weeks. The objectives of the pilot study were to analyze the reliability of the questionnaire items and to further refine them. Full details of the pilot study and the results will be presented in a separate section in this chapter. Following the final amendment of the questionnaire, an extensive data collection was carried out from April until June of 2009 in Malaysia. A total of 425 useable sets of questionnaires were collected from both local Malaysian tourists and international tourists. The amount of data collected corresponds to the 1:5 item-cases ratio as suggested by Tabachnik and Fidell (2007) and is large enough to have negligible impacts on expected non-normality of individual metric variables (Hair et. al. 1992). All the data collected went through a series of analyses such as reliability test, validity assessment via correlation analysis and multiple regression analysis before the results of the research were discussed.

\subsection{Personal Uses of Advertising}

Prior to developing a set of scales to measure attitude towards advertising on the Internet, it is important to examine the individual's advertising beliefs. It is opined that consumers are most likely to form attitudes based on these advertising beliefs. More often than not, advertising beliefs are associated with the use of advertising in consumers' daily life. In a study by Petrovici and Marinov (2007), personal uses of advertising are termed determinants of advertising. The items used to measure the construct were designed in such a way as to explain how consumers experience advertising. Personal uses of advertising as defined by Petrovici and Marinov (2007) were product information, social role/image and hedonic/pleasure. However, in order to elucidate a more comprehensive personal experience with advertising, an amendment was made to complement Tan and Chia's (2007) personal experience factors. Hence, another area i.e. falsity/no sense, was introduced to this current research.

To measure these four areas, personal advertising belief items were measured on a five-point Likert scale. The items were developed through a systematic review of past literature to best suit the current research context. Apart from replicating items from the two main studies, additional items used in earlier studies were also included in order to develop new scales. The addition was practiced after taking into consideration the relevancy of the items to this study. To examine respondents' beliefs about print advertising, television advertising and internet advertising correspondingly, all items measuring the four mentioned areas were rephrased and repeated, so that dimensionality of attitude toward advertising in three media (i.e. print, television and the Internet) could be analyzed and comparisons made. For instance, 'print advertisements are a useful source of information' is an item used to measure the product information dimension for attitude toward advertising in print media; meanwhile 'internet advertisements are a useful source of information' is another item used to measure internet advertising in the same dimension.

Firstly, product information has been found to be a significant use of advertising and it has been proved quite frequently in previous studies (Petrovici and Marinov 2007). The product information dimension measures the individual's beliefs about advertising as a valuable source of information for products or services. In this study, product information is measured by items such as 'print advertisements help me to keep up to date about products/services available in the marketplace', 'print advertisements are a useful source of information', 'print advertising is a valuable source of information about local sales/products', 'print advertising contributes to the 
knowledge about quality products', 'there is better value in advertised products in print media than unadvertised products' and 'print advertisements tell me which brands have the features I am looking for'. All items were adopted from Petrovici and Marinov (2007) except for 'there is better value in advertised products in print media than unadvertised products' which was taken from Sohail and Saeed (2004) to examine whether or not advertising in any specific media adds value to the advertised product. As mentioned earlier, the same items are repeated to measure the product information dimension for both advertising on the television and on the Internet.

Secondly, social role/image dimension describes the individual's beliefs about advertising that reflect and shape his/her personal image as well as the image of other external subjects. It is measured by Petrovici and Marinov (2007) items such as 'print advertisements tell me what persons like me are buying or using', 'print advertising has an important role in the education of children', and 'print advertising keeps me up to date with trends in various fields'; to these were added another four items previously measured by Pollay and Mittal (1993), i.e. 'print advertising helps me to know which products will or will not reflect the sort of person I am', 'there is too much sex in print advertising today', 'from print advertising I can learn about fashions and about what to buy to impress others' and 'most print advertising distorts the values of our youth'. These additional items are important to frame respondents' encounters with sex and youth social images in advertising and advertisements.

Thirdly, hedonic/pleasure is a dimension that encompasses the individual's beliefs about advertising in terms of it being entertaining, amusing and pleasurable. It is measured by 'sometimes print advertisements are even more enjoyable than other media content', 'print advertising is often amusing and entertaining', 'I like to talk to my friends about print advertisements', 'sometimes I take pleasure in thinking about what I saw, heard or read in print advertisements' and 'sometimes print advertisements bring to my mind pleasant memories'. All of the items are adopted from Petrovici and Marinov (2007) except 'sometimes print advertisements are even more enjoyable than other media content'; they had previously dropped this item but this time it is used due to its suitability.

And, finally, falsity/no sense is a dimension which explains the individual's beliefs about advertising as a source of manipulation, exaggeration or misleading information. This dimension was not previously measured by Petrovic and Marinov (2007); however, it is opined that falsity/no sense would be appropriate to exemplify negativity towards advertising. Therefore, a new scale is developed based on the items adopted from Larkin's (1977) and Tan and Chia's (2007) studies. The items are 'in general television advertising in misleading', 'print advertising should be more realistic', 'most print advertising insults the intelligence of the average consumer', 'in general, print advertisements present a true picture of the product advertised', 'print advertising often persuades people to buy things they really don't need or should not buy' and 'there are too many exaggerations in print advertising today'. Again, the same items are repeated to measure the falsity/no sense dimension for both television advertising and internet advertising.

\subsection{Attitude towards Advertising on the Internet}

In general, one's personal experience with advertising could eventually have an impact in the formation of one's personal attitude towards advertising. Similarly, one's personal attitude towards advertising in any specific media would have been a result of one's personal experience with advertising in that specific media. With the availability of items measuring consumers' personal use of advertising, this study subsequently attempts to measure attitude towards advertising in specific media. In a previous study, Tan and Chia (2007) measured this construct with a set of Likert-scaled items, for example 'Overall, I consider television advertising a bad thing', 'Overall, I like television advertising' and 'I consider television advertising to be very essential'. In the current study, however, a set of semantic differential items were used in congruence with the approach used to measure other attitudinal scales. In order to be consistent with the items used by Tan and Chia (2007), three semantic differential adjectival pairs are utilized in this study. The adjectives are good/bad, negative/positive and essential/inessential.

\section{Research Findings}

Table 1 presents the mean values, standard deviation (SD), skewness and kurtosis values of advertising beliefs dimensions rated by the respondents from their experiences with internet advertising. From Table 1, the mean scores of advertising beliefs ranged from 3.10 to 3.75 and standard deviation from 0.92 to 1.16 . The product information dimension recorded the highest overall mean score of 3.59 and standard deviation of 0.67.

The respondents gave a statement from the falsity/no sense dimension, "Internet advertisement should be more realistic", the highest mean score (Mean $=3.75, S D=0.98)$ and a statement from the social role/image dimension, "Internet advertising has an important role in the education of children", the lowest mean score (Mean $=3.10, S D$ $=1.18$ ). The range of mean scores and standard deviations of the four dimensions were as follows; for product information, the mean scores ranged from 3.46 to 3.70 and standard deviation from 0.90 to 1.05 ; for social role/image, the mean scores ranged from 3.10 to 3.69 with standard deviation from 0.96 to 1.16 ; the mean scores 
for hedonic/pleasure ranged from 3.14 to 3.40 and standard deviation from 0.96 to 1.07 ; meanwhile, the mean scores for falsity/no sense ranged from 3.25 to 3.75 with standard deviation from 0.92 to 1.08 .

The skewness and kurtosis values were also presented in Table 1 and indicated non-violation of the normality assumption. As a general rule, therefore, the data for advertising belief dimensions do not need any transformation.

Table 1. Internet advertising belief scores: mean scores and standard deviation (SD), skewness and kurtosis ( $\mathrm{N}=$ 425)

\begin{tabular}{|c|c|c|c|c|}
\hline Belief statement $^{a}$ & Mean & SD & Skewness & Kurtosis \\
\hline Product Information & 3.59 & 0.67 & -0.16 & -0.12 \\
\hline Internet advertisements are a useful source of information. & 3.70 & 1.04 & -0.53 & -0.34 \\
\hline $\begin{array}{l}\text { Internet advertisements tell me which brands have the features I am } \\
\text { looking for. }\end{array}$ & 3.64 & 0.91 & -0.48 & 0.04 \\
\hline $\begin{array}{l}\text { Internet advertisements help me to keep up to date about } \\
\text { products/services available in the marketplace. }\end{array}$ & 3.63 & 1.05 & -0.35 & -0.18 \\
\hline $\begin{array}{l}\text { Internet advertising is a valuable source of information about local } \\
\text { sales/products. }\end{array}$ & 3.57 & 0.97 & -0.38 & -0.16 \\
\hline Internet advertising contributes to the knowledge about quality products. & 3.52 & 0.90 & -0.28 & -0.15 \\
\hline $\begin{array}{l}\text { There is a better value for advertised products on the Internet than } \\
\text { unadvertised products. }\end{array}$ & 3.46 & 0.97 & -0.23 & -0.21 \\
\hline Social Role/Image & 3.40 & 0.75 & -0.08 & -0.16 \\
\hline Internet advertising keeps me up to date with trends from various fields. & 3.69 & 0.96 & -0.51 & -0.07 \\
\hline $\begin{array}{l}\text { From internet advertising I can learn about fashions and about what to } \\
\text { buy to impress others. }\end{array}$ & 3.47 & 0.96 & -0.24 & -0.21 \\
\hline $\begin{array}{l}\text { Internet advertising helps me to know which products will or will not } \\
\text { reflect the sort of person I am. }\end{array}$ & 3.36 & 1.05 & -0.34 & -0.17 \\
\hline $\begin{array}{l}\text { Internet advertisements tell me what persons like me are buying or } \\
\text { using. }\end{array}$ & 3.36 & 0.99 & -0.27 & -0.24 \\
\hline Internet advertising has an important role in the education of children. & 3.10 & 1.16 & -0.15 & -0.70 \\
\hline Hedonic/Pleasure & 3.26 & 0.72 & -0.11 & 0.30 \\
\hline $\begin{array}{l}\text { Sometimes internet advertisements are even more enjoyable than other } \\
\text { media content. }\end{array}$ & 3.40 & 1.07 & -0.37 & -0.31 \\
\hline Internet advertising is often amusing and entertaining. & 3.32 & 0.96 & -0.11 & -0.24 \\
\hline $\begin{array}{l}\text { Sometimes internet advertisements bring to my mind pleasant } \\
\text { memories. }\end{array}$ & 3.24 & 0.98 & -0.17 & -0.01 \\
\hline $\begin{array}{l}\text { Sometimes I take pleasure in thinking about what I saw, heard or read in } \\
\text { internet advertisements. }\end{array}$ & 3.21 & 1.00 & -0.19 & -0.36 \\
\hline I like to talk to my friends about internet advertisements. & 3.14 & 1.03 & -0.19 & -0.22 \\
\hline Falsity/No sense & 3.36 & 0.50 & 0.02 & 0.36 \\
\hline Internet advertisements should be more realistic. & 3.75 & 0.98 & -0.52 & -0.16 \\
\hline There are too many exaggerations in internet advertising today. & 3.63 & 0.96 & -0.50 & -0.23 \\
\hline $\begin{array}{l}\text { Internet advertising often persuades people to buy things they really } \\
\text { don't need or should not buy. }\end{array}$ & 3.38 & 1.00 & -0.25 & -0.88 \\
\hline $\begin{array}{l}\text { Most internet advertising insults the intelligence of the average } \\
\text { consumer. }\end{array}$ & 3.35 & 0.92 & -0.23 & -0.24 \\
\hline In general, internet advertising is misleading. & 3.33 & 0.96 & -0.29 & -0.24 \\
\hline $\begin{array}{l}\text { In general, internet advertisements present a true picture of the product } \\
\text { advertised. }\end{array}$ & 3.25 & 1.08 & -0.19 & -0.79 \\
\hline
\end{tabular}

${ }^{\mathrm{a}}$ Items are measured on a 5 -point Likert scale, $1=$ Strongly disagree and $5=$ Strongly agree 


\subsection{Attitudes towards Advertising on the Internet}

A correlation analysis was also run with all the constructs that are predicted to explain attitude towards advertising on the Internet $\left(\mathrm{A}_{\text {Internet }}\right)$. The correlation coefficients are presented in Table 2 together with the respective mean, standard deviation and reliability scores. All constructs were significantly correlated with the dependent measure, however Falsity/no sense has the lowest correlation recorded at $r=-1.55$. The coefficients between other constructs and the dependent measure were significant at 0.01 level and ranged from 0.42 to 0.46 . In this model, hedonic/pleasure exhibits the strongest relationship with the dependent measure $(r=0.457)$, followed by social role/image $(r=0.456)$ and product information $(r=0.419)$. For this model, the Cronbach's alpha coefficients ranged from 0.74 to 0.84 , indicating the scales' internal consistency.

Correlation analysis was also performed to justify the research hypotheses related to this model. Prior to the analysis, preliminary analyses were performed to confirm that all fundamental assumptions of normality, linearity and homoscedasticity were not violated. It was hypothesized that:

Hypothesis. Malaysia tourists' beliefs about internet advertising as a source of product information are positively related to attitudes towards advertising on the Internet.

From Table 2, correlations between product information and attitude toward internet advertising was significant and the strength is distinctly moderate $(r=0.419, \mathrm{n}=425, p<0.01)$. This signifies that high levels of product information are associated with high levels of attitude toward television advertising. At the same time, the correlation provides predictive validity of product information on attitude toward internet advertising. With this evidence, the hypothesis is supported.

Table 2. Mean, standard deviation, correlation coefficients and reliability scores for all scales $(\mathrm{N}=425)$

\begin{tabular}{llrrrrrrrr}
\hline & & Mean & $\begin{array}{l}\text { Standard } \\
\text { Deviation }\end{array}$ & Attitude-Internet & Product-Info & Socrole & Hedonic & Falsity \\
\hline Pearson & Attitude-Internet & 4.71 & 1.26 & 1 & $\mathbf{0 . 8 4}$ & & & \\
Correlation & Product-Info & 3.59 & 0.67 & 0.419 & 1 & $\mathbf{0 . 7 8}$ & & \\
& Socrole & 3.4 & 0.75 & 0.456 & 0.717 & 1 & $\mathbf{0 . 7 8}$ & \\
& Hedonic & 3.26 & 0.72 & 0.457 & 0.619 & 0.694 & 1 & $\mathbf{0 . 7 5}$ & \\
& Falsity & 3.36 & 0.5 & -0.155 & 0.152 & $.092^{\mathrm{b}}$ & $.089^{\mathrm{b}}$ & 1 & $\mathbf{0 . 7 4}$ \\
\hline
\end{tabular}

${ }^{\text {a }}$ All correlations are significant at the 0.01 level (2-tailed) unless otherwise stated;

${ }^{\mathrm{b}}$ correlation is not significant

Table 3. Regression testing the predictability of personal use of advertising on the Internet

\begin{tabular}{lcc}
\hline & \multicolumn{2}{c}{$\mathbf{A}_{\text {Internet }}$} \\
\hline Independent & Beta & t-value \\
Product information & $0.130^{*}$ & 2.091 \\
Social role/image & $0.196^{*}$ & 2.881 \\
Hedonic/pleasure & $0.240^{* *}$ & 3.989 \\
Constant & & 1.328 \\
Multiple $R$ & 0.5 & \\
$R^{2}$ & 0.25 & \\
$F$ test statistic/significance & $F(3,421)=47.691$ & \\
& $p=0.00$ &
\end{tabular}

Table 3 presents the regression analysis which was carried out to test the predictability of personal use advertising on the Internet towards $A_{\text {Internet. }}$ Some unexpected observations emerged from this model. Firstly, all variables with a significant impact were found in this model. Secondly, an examination of the standardized beta coefficients found that hedonic/pleasure was the stronger predictor of $\mathrm{A}_{\text {Internet }}$ as compared to the rest of the variables. The next most important variable was social role/image, followed by product information.

Figure 1 depicts the causal relationship between the variables. Solid lines with arrows represent the causal relationship of the tested variables while the dotted lines represent partially mediated relationships between the variables. 


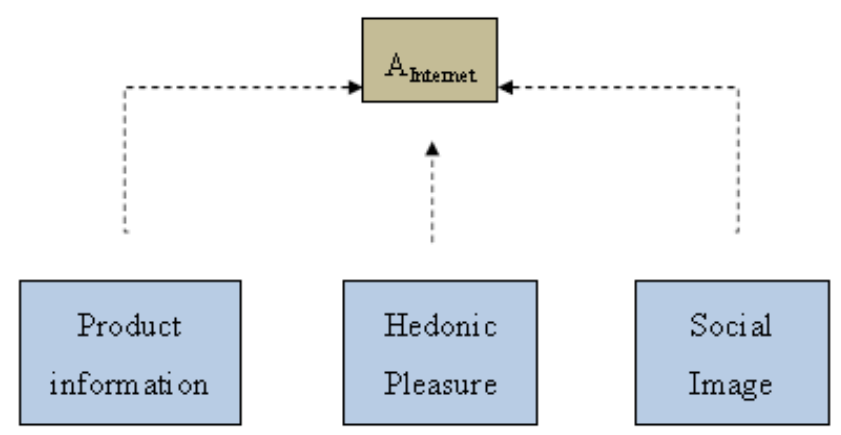

Figure 1. Model of attitude towards advertising on the Internet $\left(\mathrm{A}_{\text {Internet }}\right)$

\section{Discussion}

\subsection{Advertising on the Internet}

The findings in this study indicate that attitude toward advertising on the Internet $\left(\mathrm{A}_{\text {Internet }}\right)$ is influenced by all of the tested factors, i.e. hedonic/pleasure, social role/image as well as product information. This is not surprising as the media itself is indeed a hybrid of television, radio, newspapers, magazines, billboards, direct mail and so forth (Miller 1996). Hence, its ability to deliver more than just product information function is entirely unquestionable.

It is important to discuss two observable facts from the findings about attitude toward internet advertising. First of all, similar to the early years of the Internet, this study found that internet advertising is still exerting less influence than the traditional advertising media (Ducoffe 1996; Schlosser and Shavitt 1998). Comparatively, on average, the informants preferred television advertising to internet advertising. Although there is no immediate explanation for this scenario, it obviously shows that the domination of television advertising over the past few decades has been unrivalled, even in the midst of the social networking bandwagon with which various sorts of internet ads are linked. This is consistent with a study on advertising effectiveness, comparing web and television advertising, by Nagar (2009). According to Nagar (2009), television advertising was found to perform significantly better that web advertising in three out of six positive advertising effectiveness constructs, i.e. attention-grabbing ability, precipitating action and facilitating attitude change. Internet advertising, on the other hand, was superior only in conveying product and service information.

Secondly, unlike previous studies, this study has identified two other factors that influence favourable attitudes toward internet advertising, i.e. hedonic/pleasure and social role/image. It is well-documented in the literature that internet advertising is able to channel rich information (Leong et al. 1998; Nagar 2009; Wolin et al. 2002) and it was proved that this attribute does encourage positive attitudes towards internet advertising. However, in addition to that, this study has also discovered other factors which have seldom been reported in the past. As mentioned earlier, $A_{\text {Internet }}$ was also being influenced by the ability of internet advertising to bring fun and entertainment (hedonic/pleasure) and to reflect consumers' social and self image (social role/image). Although it is rather premature to suggest that internet advertising has grasped people's attention with its multimedia capability, it is interesting to note that a recent study by Sun and Wang (2010) has also indicated similar results. Sun and Wang (2010) examined attitudes towards online advertising across two separate samples, Chinese and Americans. In their study, a measure called value belief, which is similar to social role/image used in the present study, was one of the significant factors that predict attitudes towards online advertising among both samples. The entertainment factor, on the other hand, emerged as a significant predictor of attitudes towards online advertising in the United States. On the whole, therefore, it can justifiably be proposed that people's favourable attitudes towards advertising in this medium are due to the very hybrid nature of the Internet itself, which serves its ability to perform multimedia tasks.

\subsection{The Important Roles of Advertising Media in Malaysia's Tourism Industry}

At the moment, a huge percentage of Malaysia's annual tourism budget is dedicated to the purpose of advertising alone (refer to the overall tourism budget for 2006 and 2007 in Table 4.2 and 4.3). One of the ways to monitor the effectiveness of advertising implementation and strategy is through the feedback from the target market itself. The results of this study may help Malaysia's tourism policy-maker and marketers to fundamentally identify the level of appreciation Malaysia tourists have about advertising and, most importantly, to delve into key advertising functions that explain their attitudes towards advertising in specific media, especially the ones that are normally employed to promote Malaysia's tourism industry. 
The findings may guide all interested parties in the Malaysian tourism industry in their decisions to put into operation some other marketing communication tools for promotional purposes rather than just employing an extensive advertising strategy. In addition, the results may also help the policy-makers and marketers to design advertising strategies according to the predilections of the target market by means of advertising media and the functions which best fit and correspond to the tourist informants' experiences and thoughts. This is exceptionally important as they define dissimilar sets of orientations or functions to different kinds of advertising media which in turn determine their attitudes toward the advertising media as well as advertising in general.

Therefore, it is hoped that tourism marketers and advertisers understand how tourists react and behave in response to traditional advertising media, especially upon the arrival of the new ones, which in many cases may help to achieve their marketing objectives effectively before jumping on the bandwagon. Nonetheless, this study suggests the combined use of various advertising media in promoting Malaysia, employing the three specific advertising media, indicating fulfilment of all their constructive functions. In this respect, this implementation will uphold the essence of integrated marketing communications (IMC) in a more detailed scope of advertising.

Another area worth mentioning is the possibility of venturing into several other increasingly relevant media such as mobile advertising and online video advertising which may further intensify advertising functions, even though this may result in unwarranted advertising expenditure. Having said that, Joshi and Hanssens (2010) argued that investment in advertising has a positive effect not only on revenue and profit sales, but also on the long-term market capitalization (i.e. spending at the profit-maximizing level). Nevertheless, it is equally important to study the applicability of those media in the context of tourism prior to the implementation in order to fine-tune the advertised contents in congruence with the existing ones. This is particularly crucial as harmonization of promotional message and consistency of concept is the key to effective IMC.

\section{References}

ADMAP. (2011, March). WARC (previously known as the World Advertising Research Center). Vol. 46, No. 3.

Arens, A. F. (2006). Contemporary Advertising. New York: McGraw-Hill/Irwin.

Berry, J. W. (1980). Introduction to Methodology. In Harry, C. T., \& John, W. B. (Eds.), The Handbook of Cross-Cultural Psychology (pp. 1-29). Boston, MA: Allyn and Bacon, Inc.

Berthon, P., Pitt, L. F., \& Watson, R. T. (1996). The World Wide Web as an Advertising Medium: Toward and Understanding of Conversion Efficiency. Journal of Advertising Research, 36(1), 43-54.

Brackett, L. K., \& Carr, B. N. Jr. (2001, Sept/Oct). Cyberspace Advertising vs. Other Media: Consumer vs. Mature Student Attitudes. Journal of Advertising Research, 23-32.

Branthwaite, A., Wood, K., \& Schilling, M. (2000). The Medium is Part of the Message - The Role of Media for Shaping the Image of a Brand. ARF/ESOMAR Conference, Rio de Janeiro, Brazil, 12-14 November.

Burns, K. S., \& Lutz, R. J. (2006). The Function of Format: Consumer Responses to Six On-Line Advertising Formats. Journal of Advertising, 35(1), 53-63. http://dx.doi.org/10.2753/JOA0091-3367350104

Bush, A. J., Bush, V., \& Harris, S. (1998, Mar/Apr). Advertiser Perceptions of the Internet as a Marketing Communications Tool. Journal of Advertising Research, 17-27.

Chaffey, D. (2007). Internet Marketing: Strategy, Implementation and Practice (4th ed.). Prentice-Hall, England.

Chaffey, D. (2009). E-Business and E-Commerce Management: Strategy, Implementation and Practice (4th ed.). Prentice-Hall, England.

Cheung, C. M., \& Lee, M. K. O. (2006). Understanding Consumer Trust in Internet Shopping: A Multidisciplinary Approach. Journal of the American Society for Information Science and Technology, 57(4), 479-492. http://dx.doi.org/10.1002/asi.20312

Cho, C. (1999). How Advertising Works on the WWW: Modified Elaboration Likelihood Model. Journal of

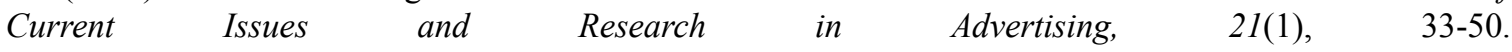
http://dx.doi.org/10.1080/10641734.1999.10505087

Chu, S., \& Kim, Y. (2011). Determinants of Consumer Engagement in Electronic Word-of-Mouth (eWOM) in Social Networking Sites. International Journal of Advertising, 30(1), 47-75. http://dx.doi.org/10.2501/IJA-30-1-047-075

Ducoffe, R. H., Sandler, D., \& Secunda, E. (1996). A Survey of Senior Agency, Advertiser, and Media executives on the Future of Advertising. Journal of Current Issues and Research in Advertising, 18(1), 1. http://dx.doi.org/10.1080/10641734.1996.10505036 
Duncan, T. (2002). IMC: Using Advertising \& Promotion to Build Brands. New York: McGraw-Hill/Irwin.

Hair, J. F., Black, W. C., Babin, B. J., \& Anderson, R. E. (1992). Multivariate Data Analysis: A Global Perspective. New Jersey: Pearson Education Inc.

Hawkins, D. T. (1994). Electronics Advertising: On Online Information Systems. Online.

Jayawardhena, C., Wright, L.-T., \& Dennis, C. (2007). Consumers online: intentions, orientations and segmentation. International Journal of Retail and Distribution Management, 35(6). http://dx.doi.org/10.1108/09590550710750377

Joshi, A., \& Hanssens, D. M. (2010). The Direct and Indirect Effects of Advertising Spending on Firm Value. Journal of Marketing, 74(1), 20-23. http://dx.doi.org/10.1509/jmkg.74.1.20

Katerattanakul, P. (2002). Framework of Effective Website Design for Business-to-Consumer Internet Commerce. INFOR, 40(1), 57-69.

Kelly, L., Kerr, G., \& Drennan, J. (2010). Avoidance of Advertising in Social Networking Sites: The Teenage Perspective. Journal of Interactive Advertising, 10(2), 16-27.

Larkin, E. F. (1977). A Factor Analysis of College Students Attitudes toward Advertising. Journal of Advertising, $6(2), 42-46$.

Lee, M. K. O., \& Turban, E. (2006). A Trust Model for Consumer Internet Shopping. International Journal of Electronic Commerce, 6(1), 75-91.

Lei, R. M. (2000). An Assessment of the World Wide Web as an Advertising Medium. Social Science Journal, 37(3), 465-471. http://dx.doi.org/10.1016/S0362-3319(00)00081-1

Leiss, W., Kline, S., Jhally, S., \& Botterill, J. (2005). Social Communication in Advertising: Consumption in the Mediated Marketplace. New York: T\&F Informa.

Leong E. K. F., Huang, X., \& Stanners, P. (1998, Sept/Oct). Comparing the Effectiveness of the Web Site with Traditional Media. Journal of Advertising Research, 44-51.

Lim, K. H., Sia, C. L., Lee, M. K. O., \& Benbazat, I. (2006). Do I Trust You Online, and If So, Will I Buy? An Empirical Study of Two Trust-Building Strategies. Journal of Management Information Systems, 23(2), 233-266. http://dx.doi.org/10.2753/MIS0742-1222230210

Mackenzie, S. B., \& Lutz, R. J. (1989). An Empirical Examination of the Structural Antecedents of Attitude toward the $\mathrm{Ad}$ in an Advertising Pretesting Context. Journal of Marketing, 53(2), 48-65. http://dx.doi.org/10.2307/1251413

Mangold, W. G., \& Faulds, D. J. (2009). Social Media: The New Hybrid Element of the Promotion Mix. Business Horizons, 5(4), 357-365. http://dx.doi.org/10.1016/j.bushor.2009.03.002

Miller, S. E. (1996). Civilizing Cyberspace: Policy, Power, and the Information Superhighway. New York: ACM Press.

Mills, J. E., Jung, K. L., \& Douglas, A. C. (2007). Exploring Perceptions of US State Tourism Organizations' Web Advertising Effectiveness. Asia Pacific Journal of Tourism Research, 12(3), 245-266. http://dx.doi.org/10.1080/10941660701416820

Murray, J. Y., Kotabe, M., \& Zhou, J. N. (2005). Strategic Alliance-Based Sourcing and Market Performance: Evidence from Foreign Firms Operating in China. Journal of International Business Studies, 36(2), 187-208. http://dx.doi.org/10.1057/palgrave.jibs. 8400120

Nagar, K. (2009, September). Advertising Effectiveness in Different Media: A Comparison of Web and Television Advertising. IIMB Management Review, 245-260.

O’Guinn, T. C., Allen, C. T., \& Semenik, R. J. (2006). Advertising \& Integrated Brand Promotion. Thomson South-Western.

Petrovici, D., \& Marinov, M. (2007). Determinants and Antecedents of General Attitudes towards Advertising. European Journal of Marketing, 41(3/4), 307-326. http://dx.doi.org/10.1108/03090560710728354

Podsakoff, P. M., MacKenzie, S. B., Lee, J. Y., \& Podsakoff, N. P. (2003). Common Method Biases in Behavioural Research: A Critical Review of the Literature and Recommended Remedies. Journal of Applied Psychology, 88(5), 879-903. http://dx.doi.org/10.1037/0021-9010.88.5.879

Pollay, R. W., \& Mittal, B. (1993). Here's the Beef: Factors, Determinants, and Segments in Consumer Criticism 
of Advertising. Journal of Marketing, 57(3), 99-114. http://dx.doi.org/10.2307/1251857

Schlosser, A. E., \& Shavitt, S. (1999). Survey of Internet Users' Attitude toward Internet Advertising. Journal of Interactive Marketing, 13(3), 34-54. http://dx.doi.org/10.1002/(SICI)1520-6653(199922)13:3<34::AID-DIR3>3.0.CO;2-R

Sohail, S., \& Saeed, M. (2004). Public Attitudes Towards Advertising in an Emerging Southeast Asian Nation: An Empirical Study. Journal of International Marketing \& Marketing Research, 29(1), 21-36.

Sun, S., \& Wang, Y. (2010). Familiarities, Beliefs, Attitudes and Consumer Responses toward Online Advertising in China and the United States. Journal of Global Marketing, 23(2), 127-138. http://dx.doi.org/10.1080/08911761003673454

Tabachnik, B. G., \& Fidell, L. S. (2007). Using Multivariate Statistics. Boston: Pearson Education.

Tan, S. J., \& Chia, L. (2007). Are We Measuring the Same Attitude? Understanding media Effects on Attitude towards Advertising. Marketing Theory, 7(4), 353-377. http://dx.doi.org/10.1177/1470593107083162

Walmsley, A. (2007, September). New Media: The Age of the Trialogue. The Marketer, 12.

Wolin, L. D., Korgaonkar, P., \& Lund. D. (2002). Beliefs, Attitudes and Behaviour towards Web Advertising. International Journal of Advertising, 21(1), 87-113.

Wu, S., Chen, J., \& Liu, P. (2011). The Relationship Model of Internet Advertising Effect - An Examination of Computer Advertising. Journal of International Marketing and Marketing Research, 36(1), 3-23.

Wu, S., Wei, P., \& Chen, J. (2008). Influential Factors and Relational Structure of Internet Banner Advertising in the Tourism Industry. Tourism Management, 29, 221-236. http://dx.doi.org/10.1016/j.tourman.2007.03.020 